\title{
Knockdown resistance mutations contributing to pyrethroid resistance in Aedes aegypti population, Saudi Arabia
}

Ommer Dafalla, ${ }^{1}$ Adel Alsheikh, ${ }^{1}$ Waheed Mohammed, ${ }^{1}$ Khalid Shrwani, ${ }^{1}$ Feras Alsheikh, ${ }^{2}$ Yahya Hobani ${ }^{1}$ and Elsiddig Noureldin'.

${ }^{1}$ Saudi Centre for Disease Control \& Prevention, Ministry of Health, Jazan, Saudi Arabia (Correspondence to: Omer Dafalla: omerosa@yahoo.com).

${ }^{2}$ Faculty of Public Health \& Tropical Medicine, Jazan University, Jazan, Saudi Arabia.

\begin{abstract}
Background: Dengue is endemic in Saudi Arabia especially in Jeddah, Makkah, Asir, and Jazan areas where pyrethroids are widely used to control the vector, Aedes aegypti. Resistance of Ae. aegypti to pyrethroid insecticides has been reported from most of these areas.
\end{abstract}

Aims: The present study was carried out in Jazan region in south-west Saudi Arabia to explore the resistance status of Ae. aegypti to pyrethroids and the consequent underlying mechanisms.

Methods: Three pyrethroids (permethrin, lambda-cyhalothrin, and cyfluthrin) were used to investigate the resistance status of Ae. aegypti adults following World Health Organization (WHO) standard methods: PCR and sequencing techniques were used to detect the S989P, V1016G and F1534C kdr mutations.

Results: Ae. aegypti populations were susceptible to cyfluthrin and having a possibility of resistance to permethrin while resistant to lambda-cyhalothrin. Three potential kdr mutations were detected for the first time in Ae. aegypti population, F1534C, V106G, and S989P. It was found that F1534C often co-exists with V1016G and this haplotype was strongly associated with permethrin and lambda-cyhalothrin resistance. On the other hand, S989P mutation was detected as RR in 18.8\% with a low-frequency rate $(\mathrm{R})$ of $18.8 \%$, and in $55.5 \%$ as $\mathrm{R}$ with $58.3 \%$ frequency rate in permethrin and lambda-cyhalothrin-resistant female mosquitoes, respectively.

Conclusions: Early detection of resistance alleles should be considered the essential tool for the successful implementation of insecticide resistance management strategies by providing early warning of insect resistance.

Keywords: dengue, pyrethroids, Aedes aegypti, resistance, mutations

Citation: Dafalla O; Alsheikh A; Mohammed W; Shrwani K; Alsheikh F; Hobani Y; Noureldin E. Knockdown resistance mutations contributing to pyrethroid resistance in Aedes aegypti population, Saudi Arabia. East Mediterr Health J. 2019;25(12):905-913. https://doi.org/10.26719/emhj.19.081

Received: 27/12/17; accepted: 14/05/18

Copyright @ World Health Organization (WHO) 2019. Some rights reserved. This work is available under the CC BY-NC-SA 3.0 IGO license (https:// creativecommons.org/licenses/by-nc-sa/3.o/igo).

\section{Introduction}

The Aedes aegypti mosquito is by far the most competent vector of many arboviral diseases, including dengue, yellow fever, chikungunya, Zika and West Nile. Dengue fever and dengue haemorrhagic fever have consequently spread through more than 100 countries in tropical and subtropical zones, resulting in more than half of the world population being at risk (1). Using insecticides to control vector-borne diseases is still the main intervention although efforts to introduce licensed vaccines have progressed greatly.

Dengue is endemic in Saudi Arabia, especially in the Jeddah, Mecca, Asir and Jazan areas. Around 12131 confirmed cases were reported from Jeddah and Mecca between 2013 and 2015 (2). Likewise, 1790 confirmed cases were reported from Jazan region between 2005 and 2016, with a severe outbreak in 2016 (555 cases). The number of confirmed cases from Jazan region in 2017 was 320 (3).

Knockdown resistance $(\mathrm{kdr})$ is a mechanism that describes cases of resistance to pyrethroid as a result of target site insensitivity due to point mutations in the insect voltage-gated sodium channel (VGSC) regulatory protein, which block pyrethroid and DDT action (genetic makeup) (4). Several kdr mutations have been reported in Ae. aegypti populations worldwide; these include G923V, L982W, I1011M/V,S989P, V1016G/I, F1534C and D1763Y (5).

The majority of resistance-associated mutations are found in segment 6 of domain II (IIS6) and domain III (IIIS6) of the sodium channel gene. For instance, valine to glycine in domain II (V1016G) is associated with resistance to type I and type II pyrethroids, such as permethrin and deltamethrin (6), while phenylalanine to cysteine substitution at position 1534 within domain III (F1534C) is associated with resistance to type I pyrethroids (7). On the other hand, serine to proline (S989P) in domain II in VGSC has also been associated with pyrethroid resistance (8) and valine to isoleucine transversion in domain II (V1016I) contributed to Ae. Aegypti pyrethroids resistance in Latin America (9). However, S989P has not been found alone (10).

The kdr mutations in Ae. aegypti have been reported from Singapore (11), China (12,13) and Greece (13), and 1534Leu and 1534Ser have been found in the United States of America (14). 
Few studies have been reported on the resistance status of Ae. aegypti to insecticides in Saudi Arabia (15-17). Furthermore, studies on mechanisms of resistance to pyrethroids in Ae. aegypti populations from Saudi Arabia are lacking. Only one has been conducted in Jeddah and Mecca, in the western region of Saudi Arabia (2). This study reported 2 mutations (V1016G and S989P) in Ae. aegypti, which were shown to be responsible for the resistance of permethrin and deltamethrin.

To the best of our knowledge, no studies have been carried out to investigate the resistance mechanisms of Ae. aegypti to pyrethroid insecticides in Jazan region. The aim of this study is therefore to explore the resistance status of Ae. aegypti to pyrethroids and the underlying mechanisms.

\section{Methodology}

\section{Study area}

Jazan region is situated in the subtropical zone, south-western Saudi Arabia, lies between $16^{\circ} 12^{\prime}$, and $18^{\circ} 25^{\prime}$ north. It is surrounded by the Red Sea $(260 \mathrm{~km})$ from the west, by Yemen $(120 \mathrm{~km})$ from the south and east and by Asir region from the north, with a total area of about $22000 \mathrm{~km}^{2}$ and a population of 1.3 million (18).

\section{Adult bioassay}

This study was carried out in 2017. Larvae of Ae. aegypti were collected from Gizan City and were left to develop until adult under laboratory conditions, $25 \pm 2{ }^{\circ} \mathrm{C}$ and $75 \%$ relative humidity with a constant photoperiod; $12 \mathrm{~h}$ light, $12 \mathrm{~h}$ dark.

About 100 sugar-fed, 3-5-day-old Ae. aegypti female mosquitoes were used for each of permethrin, lambdacyhalothrin and cyfluthrin for bioassay testing. A batch of 25 adults was introduced into a holding tube before being exposed to insecticide-impregnated papers. Equal numbers of control tests were also carried out by exposing mosquitoes to insecticides-free papers. The experiment was replicated 4 times. After a period of exposure of 60 min under laboratory conditions $\left(25 \pm 2{ }^{\circ} \mathrm{C}\right.$ and $75 \%$ relative humidity with a constant photoperiod; $12 \mathrm{~h}$ light, $12 \mathrm{~h}$ dark), all mosquitoes were transferred to new tubes, provided with 10\% sugar solution and held for 24 hours recovery period (19). Mortality was recorded and resistance status was determined as per WHO criteria, i.e., a population is considered susceptible if the mortality rate is $(98-100 \%)$, having a possibility of resistance $90-$ $97 \%$ and resistant $<90 \%(20)$.

\section{Insecticides}

The insecticides used in this study for the adult bioassay tests were the diagnostic dosages as specified in the WHO standard methods. The insecticides were obtained from the WHO Collaborating Centre in Malaysia (Vector Control Research Unit, School of Biological Sciences, Universiti Sains Malaysia, Penang). Adults were tested against 3 pyrethroids (permethrin $0.75 \%$, lambda-cyhalothrin $0.05 \%$ and cyfluthrin $0.15 \%$ ).

\section{Mosquito samples}

After adult bioassay, we used the resistant and susceptible mosquitoes against the 3 pyrethroids to detect $\mathrm{kdr}$ mutations.

We used 16 permethrin-resistant mosquitoes, 18 lambda-cyhalothrin-resistant mosquitoes, 15 permethrinsusceptible mosquitoes, 20 lambda-cyhalothrinsusceptible mosquitoes and 20 cyfluthrin-susceptible mosquitoes as samples to detect the S989P, V1016G and F1534C kdr mutations.

\section{DNA extraction}

After removing the mosquito abdomen, samples were homogenized individually using a mortar and pestle (mini borosilicate glass chamber length $60 \mathrm{~mm}$ pestle, diameter $9.0 \mathrm{~mm} 3.0 \mathrm{~mL}$, Fisherbrand) in $100 \mu \mathrm{L}$ of Minimum Essential Media (EuroClone, UK).

We extracted DNA from the stored homogenate using RealLine DNA-Extraction 2 kit (BIORON Diagnostics, Ludwigshafen, Germany) following the manufacturer's recommendations. The extracted DNA was stored at $-86^{\circ} \mathrm{C}$ till the next procedure.

\section{Detection of S989P, V1016G and F1534C kdr mutations}

To detect S989P, V1016G and F1534C mutations, primers (Table 1) and AS-PCR were used according to the procedure described by Li et al. (21).

We carried out AS-PCR in 2 mix reactions for each sample to detect 1 mutation. The 2 mix reactions of 25 $\mu \mathrm{L}$ contained the same reagents $\left[12.5 \mu \mathrm{l}\right.$ GoTag ${ }^{\circledR} \mathrm{G} 2$ green master mix ready-to-use (Promega, Madison, Wisconsin), $3 \mu \mathrm{l}$ DNA sample] except that 1 mix contained $25 \mu \mathrm{M}$ of each of the mutant-specific primers and the other contained susceptible-specific primers.

The thermal cycling incubations were as follow: $94^{\circ} \mathrm{C}$ initial denaturation for $5 \mathrm{~min}$ followed by 35 cycles of denaturation at $94^{\circ} \mathrm{C}$ for $30 \mathrm{~s}$, annealing at $60^{\circ} \mathrm{C}$ (for V1016G and $\mathrm{F} 1534 \mathrm{C}$ ) or $62^{\circ} \mathrm{C}$ (S989P) for $30 \mathrm{~s}$ and extension at $72{ }^{\circ} \mathrm{C}$ for $60 \mathrm{~s}$ and a final extension at $72{ }^{\circ} \mathrm{C}$ for $5 \mathrm{~min}$. The PCR products were analysed using gel electrophoresis (1.5 agarose in Tris-Acetate EDTA buffer) staining with ethidium bromide. The visualization was carried out using Gel Doc XR Imaging System (Bio-Rad, Hercules, California).

\section{Sequencing and bioinformatics analysis}

Purification and standard sequencing for PCR products were performed by Macrogen, Korea. Sequencing reactions were performed in a MJ Research PTC-225 Peltier Thermal Cycler using a ABI PRISM BigDyeTM Terminator Cycle Sequencing Kits with Applied Biosystems AmpliTaq DNA polymerase (FS enzyme) (Thermo Fisher Scientific, Waltham, Massachusetts) following the proto- 


\begin{tabular}{|c|c|c|c|}
\hline Mutation & Primer & Sequence $5-3$ & $\begin{array}{l}\text { PCR product size } \\
\text { (bp) }\end{array}$ \\
\hline \multirow[t]{4}{*}{ S989P } & Outer M1 - For & AATGATATTAACAAAATTGCGC & 594 \\
\hline & Outer $\mathrm{M} 1$ - Rev & GCACGCCTCTAATATTGATGC & \\
\hline & Inner $\mathrm{M} 1$ - S & GCGGCGAGTGGATCGAAT & 240 \\
\hline & Inner $\mathrm{M} 1$ - P & GCGGCGAGTGGATCGAAC & 240 \\
\hline \multirow[t]{4}{*}{ V1016G } & Outer M2- For & GCCACCGTAGTGATAGGAAATC & 592 \\
\hline & Outer M2 - Rev & CGGGTTAAGTTTCGTTTAGTAGC & \\
\hline & Inner $\mathrm{M} 1$ - V & GTTTCCCACTCGCACAGGT & 348 \\
\hline & Inner $\mathrm{M} 1$ - G & GTTTCCCACTCGCACAGGG & 348 \\
\hline \multirow[t]{4}{*}{ F1534C } & Outer $\mathrm{M}_{3}$ - For & GGAGAACTACACGTGGGAGAAC & 517 \\
\hline & Outer $\mathrm{M}_{3}-\mathrm{Rev}$ & CGCCACTGAAATTGAGAATAGC & \\
\hline & Inner $\mathrm{M} 1$ - F & GCGTGAAGAACGACCCGA & 248 \\
\hline & Inner $\mathrm{Ml}$ - C & GCGTGAAGAACGACCCGC & 248 \\
\hline
\end{tabular}

cols recommended by the manufacturer. The sequences were searched for sequence similarity through BLAST (22), and compared to reference sequences in BLAST and downloaded from GenBank (www.ncbi.nlm.nih.gov/genbank/).

\section{Results}

\section{Adult bioassay}

After a 24-hour recovery period from the 60-min insecticide exposure, the adult bioassay showed that the population of Jazan Ae. aegypti mosquitoes was susceptible to cyfluthrin (100\%) and resistant to permethrin (84\%) and lambda-cyhalothrin (77\%) (Table 2).

\section{AS-PCR of kdr mutations in resistant Aedes aegypti mosquito samples}

AS-PCR is considered effective in determining the $k d r$ mutations S989P, V1016G and F1534C in individual mosquitoes; these may be responsible for resistance to cyfluthrin, permethrin and lambda-cyhalothrin pyrethroids in Jazan region. Figure 1 and Tables 3 and 4 summarize the presence of the 3 mutations and mutation frequencies $(\mathrm{R} \%=\mathrm{R} \mathrm{R} \%+(0.5 \times \mathrm{RS} \%)$.

From all the resistant mosquito samples tested against lambda-cyhalothrin, 1 sample was observed as heterozygous $[\mathrm{RS} \%=\mathrm{RS} /($ total samples $) \times 100]$ for the 3 mutations.
The S989P mutation was not detected $[\mathrm{ND} \%=(\mathrm{ND} /$ (total samples) $\times 100]$ in 13 samples $(81.2 \%)$ resistant to permethrin and 7 samples (39\%) resistant to lambdacyhalothrin. This mutation was detected as homozygous $[R R \%=(R R /($ total samples $) \times 100]$ in 3 out of 16 permethrinresistant samples (with low frequency $18.8 \%$ ), whereas in 18 lambda-cyhalothrin resistant samples it was detected in 1 sample (RS, 5.5\%) and 10 samples (RR, 55.5\%) with frequency $58.3 \%$.

The V1016G and F1534C mutations presented in all resistant samples for the 3 pyrethroids used, with high frequency, sometimes reaching $100 \%$ as in the samples resistant to cyfluthrin and permethrin, and decreasing to $97.2 \%$ in the samples resistant to lambda-cyhalothrin because 1 sample expressed as RS.

\section{AS-PCR of kdr mutations in susceptible Aedes aegypti mosquito samples}

The S989P and F1534C mutations were detected as RS with low frequency, ranging from $2.5-10.0 \%$ in the 3 pyrethroid-susceptible samples (Table 5).

Likewise, mutation V1016G was expressed as RS in 55\% of the cyfluthrin-susceptible and lambda-cyhalothrinsusceptible samples, and $67 \%$ of the permethrinsusceptible samples. It was also detected as RR in $15 \%$ of the cyfluthrin-susceptible and $13 \%$ of the permethrinsusceptible-samples. The V1016G mutation frequency ranged from $22.5 \%$ to $46.5 \%$.

\begin{tabular}{lccc}
\hline Table 2 Bioassay test for susceptibility to three pyrethroids in adult Aedes aegypti mosquitoes, Jazan region of Saudi Arabia, 2017 \\
$\begin{array}{l}\text { Insecticide } \\
\text { No. mosquitoes tested }\end{array}$ & $\begin{array}{c}\text { Susceptibility (\%) } \\
\text { Resistance status }\end{array}$ \\
Cyfluthrin & 100 & 100 & Susceptible \\
Permethrin & 100 & 84 & Resistant \\
Lambda-cyhalothrin & 100 & 77 & Resistant \\
\hline
\end{tabular}




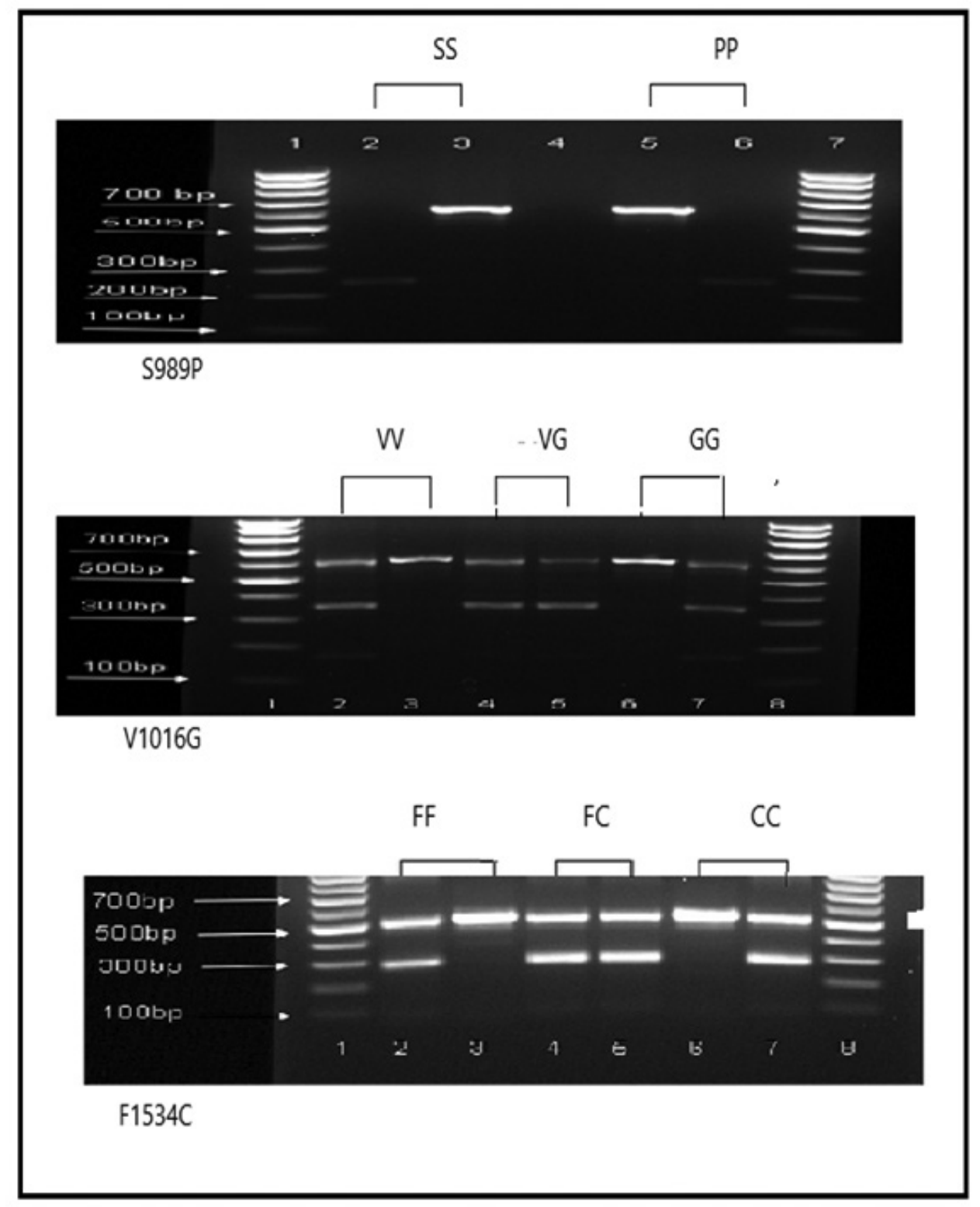

\section{Sequencing results}

Sequencing of the F1534C mutation revealed that it is in close similarity to some Asian VGSCs, e.g. India (gen bank accession number KM519597.1 and KM677280.1), Thailand (gen bank accession number EU792890.1), Japan (gen bank accession number AB909019.1) and the United States of America (gen bank accession number KC107440.1).

\section{Discussion}

In Saudi Arabia, entomological surveys indicated 4 Aedes species; Ae. vittatus, Ae. vexans arabiensis, Ae. aegypti and Ae. caspius (23). Among these, Ae. aegypti is known as the important vector of dengue fever in the Jazan region. The resistance of this species to pyrethroid insecticides has been reported in many countries worldwide, e.g. Grand
Cayman, Mexico, China, Thailand, Malaysia, Brazil, Latin America and Indonesia (24).

We found that the susceptibility of adult Ae. aegypti to cyfluthrin was100\%. Similar findings were obtained in a previous study from the Jazan region (15). However, our finding was greater than that previously reported from Mecca (90\%) (16). The logical, conventional and frequently repeated explanation that comes to mind this susceptibility to cyfluthrin is that the chemical was recently introduced to the region and the narrow-spread of its use did not provide an opportunity for selective insecticide resistance in Ae. aegypti mosquitoes.

On other hand, this study reflected the high level of resistance that the adult Ae. aegypti population exhibited to lambda-cyhalothrin (susceptibility rate $77 \%$ ) and permethrin (mortality rate $84 \%$ ) in the Jazan region. These findings confirm the findings of a previous study 


\begin{tabular}{|c|c|c|c|c|c|c|c|c|c|c|c|c|c|}
\hline \multirow[t]{3}{*}{ Insecticide } & \multirow{3}{*}{$\begin{array}{c}\text { No. of } \\
\text { samples }\end{array}$} & \multicolumn{12}{|c|}{ Mutation } \\
\hline & & \multicolumn{4}{|c|}{ F1534C } & \multicolumn{4}{|c|}{ V1016G } & \multicolumn{4}{|c|}{ S989P } \\
\hline & & ND & $\mathbf{R} \mathbf{R}$ & RS & SS & N.D & $\mathbf{R R}$ & RS & SS & ND & $\mathbf{R R}$ & RS & SS \\
\hline Cyfluthrin & 0 & 0 & 0 & 0 & 0 & 0 & 0 & 0 & 0 & 0 & 0 & 0 & 0 \\
\hline Permethrin & 16 & 0 & 16 & 0 & 0 & 0 & 16 & 0 & 0 & 13 & 3 & 0 & 0 \\
\hline Lambda-cyhalothrin & 18 & 0 & 17 & 1 & 0 & 0 & 17 & 1 & 0 & 7 & 10 & 1 & 0 \\
\hline
\end{tabular}

$N D=$ not detected $; R R=$ resistant mutant homozygote $; R S=$ mutant heterozygote $; S S=$ susceptible homozygote.

\begin{tabular}{|c|c|c|c|c|c|c|c|c|c|c|c|c|c|}
\hline \multirow[t]{3}{*}{ Insecticide } & \multirow{3}{*}{$\begin{array}{c}\text { No. of } \\
\text { samples }\end{array}$} & \multicolumn{12}{|c|}{ Mutation } \\
\hline & & \multicolumn{4}{|c|}{ S989P (\%) } & \multicolumn{4}{|c|}{ V1016G (\%) } & \multicolumn{4}{|c|}{ F1534C (\%) } \\
\hline & & SS + ND & RS & $\mathbf{R R}$ & $\mathbf{R}$ & SS + ND & RS & $\mathbf{R R}$ & $\mathbf{R}$ & SS + ND & RS & $\mathbf{R R}$ & $\mathbf{R}$ \\
\hline Cyfluthrin & 0 & 0 & 0 & 0 & 0 & 0 & 0 & 0 & 0 & 0 & 0 & 0 & 0 \\
\hline Permethrin & 16 & 81.2 & 0.0 & 18.8 & 18.8 & 0.0 & 0.0 & 100.0 & 100 & 0.0 & 0.0 & 100 & 100 \\
\hline $\begin{array}{l}\text { Lambda- } \\
\text { Cyhalothrin }\end{array}$ & 18 & 39 & 5.5 & 55.5 & 58.3 & 0.0 & 5.6 & 94.4 & 97.2 & 0.0 & 5.6 & 94.4 & 97.2 \\
\hline
\end{tabular}

$S S=$ susceptible homozygote; $N D=$ not detected $; R S=$ mutant heterozygote; $R R=$ resistant mutant homozygote; $R=$ mutation frequencies.

carried out in the Jazan region, (15) and were identical to the findings for lambda-cyhalothrin obtained in a study from Mecca (16). The resistance to permethrin agrees with finding obtained from Thailand (25), however, they contrast with the findings of a study from India in which adult Ae. aegypti and Ae. albopictus were found to be susceptible to permethrin (26).

Permethrin and lambda-cyhalothrin resistance could have resulted from the widespread, extensive and successive use of these pyrethroids for more than 10 years in control programmes to limit the population of the vectors in the region. Moreover, the use of pyrethroids to control agricultural pests has also accelerated the development of physiological resistance in these vectors. Likewise, the increased use of low concentration household pesticides aerosols has also accelerated resistance to this chemical (27). It is worth noting that resistance to pyrethroids may also have resulted from the use of DDT in the region as they share the same target in the voltage-gated sodium channel.

The primary target sites of pyrethroids are voltagegated sodium channels (VGSCs) (28) and the kdr and its mutations are highly related to reducing neuronal sensitivity to pyrethroids in several insects, including mosquitoes (29). Detection of these mutations by molecular markers could provide a useful and rapid screening tool for monitoring resistance and helping to target chemical application for vector control (30). The kdr mutations have been reported in Ae. aegypti worldwide, e.g. G923V, L982W, I1011M/V, S989P, V1016G/I, F1534C and D1763Y (31) V1023G, F1565C, I1018M, I1018V, S996P and D1794Y (32).

Three of these mutations have a direct role in pyrethroid resistance, either individually or in combination: V1016G/I (33), S989P (30) and F1534C (7).

In the present study, $3 \mathrm{kdr}$ mutations were detected for the first time in the Ae. aegypti population of Jazan region: F1534C, S989P, and V1016G. We confirmed the presence of the combined mutations (F1534C and V1016G) which are responsible for resistance to permethrin and lambda-cyhalothrin in the adult Ae. aegypti population. It is known that the F1534C kdr mutation in the IIIS6 NaV segment is the most prevalent in the population of Ae. aegypti worldwide and its role in pyrethroids resistance is well defined, either alone or in combination with other kdr mutations (34).

Our results revealed that $\mathrm{F} 1534 \mathrm{C}$ and V106G mutations were detected as homozygous (RR) in all female mosquitoes resistant to permethrin with $100 \%$ frequency, whereas $94.4 \%$ were RR with frequency $97.2 \%$ for the 2 mutations in lambda-cyhalothrin-resistant samples. This confirms that F1534C often co-exists with V1016G and this haplotype was strongly associated with permethrin and lambda-cyhalothrin resistance. Similar mutations were detected at high frequency for V1016G, S989P, and F1534C in Mecca and Jeddah (700 km north of Jazan) (2), while in Thailand the V1016G mutation appears to always co-occur with S989P (35).

The combined $\mathrm{kdr}$ mutations responsible for deltamethrin resistance in the Ae. aegypti populations in Jeddah and Mecca were V1016G and S989P (2), while in our study resistance to permethrin and lambda-cyhalothrin resulted from combined V1016G and F1534C mutations. This disparity may be related to the discrepancies in the insecticides used to control vector-borne diseases in the 3 areas. Additionally, it is widely accepted that F1534C mutation alone confers permethrin resistance (36). The combined V1016G and F1534C mutations have been 


\begin{tabular}{|c|c|c|c|c|c|c|c|c|c|c|c|c|c|}
\hline \multirow[t]{2}{*}{ Insecticide } & \multirow{2}{*}{$\begin{array}{c}\text { No. of } \\
\text { samples }\end{array}$} & \multicolumn{4}{|c|}{ S989P } & \multicolumn{4}{|c|}{ V1016G } & \multicolumn{4}{|c|}{ F1534C } \\
\hline & & SS & RS & $\mathbf{R} \mathbf{R}$ & ND & SS & RS & $\mathbf{R} \mathbf{R}$ & ND & SS & RS & $\mathbf{R} \mathbf{R}$ & ND \\
\hline & & \multicolumn{12}{|c|}{ Number } \\
\hline Cyfluthrin & 20 & 14 & 1 & 0 & 5 & 6 & 11 & 3 & 0 & 16 & 4 & 0 & 0 \\
\hline Permethrin & 15 & 11 & 3 & 0 & 1 & 3 & 10 & 2 & 0 & 13 & 2 & 0 & 0 \\
\hline \multirow[t]{2}{*}{ Lambda-Cyhalothrin } & 20 & 18 & 2 & 0 & o & 9 & 11 & 0 & 0 & 18 & 2 & 0 & 0 \\
\hline & & \multicolumn{12}{|c|}{ Frequency (\%) } \\
\hline Cyfluthrin & 20 & 95 & 5 & 0.0 & 2.5 & 30 & 55 & 15 & 42.5 & 80 & 20 & 0.0 & 0 \\
\hline Permethrin & 15 & 80 & 20 & 0.0 & 10 & 20 & 67 & 13 & 46.5 & 86.6 & 13.4 & 0.0 & 0 \\
\hline Lambda-Cyhalothrin & 20 & 90 & 10 & 0.0 & 5 & 45 & 55 & 0.0 & 22.5 & 90 & 10 & 0.0 & 0 \\
\hline
\end{tabular}

$S S=$ susceptible homozygote. $R S=$ mutant heterozygote. $R R=$ resistant mutant homozygote $; \mathrm{ND}=$ not detected .

shown to increase the resistance to deltamethrin in Ae. aegypti populations of Brazil and Mexico (37,38).

The S989P mutation, on other hand, was detected as $R R$ in $18.8 \%$ with low-frequency rate $(\mathrm{R})$ of $18.8 \%$ and in $55.5 \%$ with (R) $58.3 \%$ in permethrin-resistant and lambda-cyhalothrin-resistant samples, respectively. We speculate from the presence of the S989P mutation as RR in 3 permethrin-resistant (out of 16 ), and undetected in 13 resistant samples that this mutation was negatively correlated to permethrin resistance. This finding agrees with the results of Du et al. (34), who reported that S989P mutation has no effect on permethrin sensitivity on its own or in combination with the V1016G mutation.

Similarly, the V1016G mutation appeared as homozygous (RR) and heterozygous (RS) at high frequency in some samples susceptible to permethrin, cyfluthrin and lambda-cyhalothrin.

The 1534 mutation was never detected as RR, yet observed as heterozygous (RS) with low-frequency in the same samples. Apparently, the effect of the V1016G and S989P mutations on resistance to permethrin and lambda-cyhalothrin pyrethroids appears to be weaker than that of the F1534c mutation.

\section{Conclusion}

In this study, cyfluthrin was found to be the only effective Pyrethroid used in Jazan region against adult Ae. aegypti. The combination of F1534C and V1016G mutations were found most common in the resistance of the adults Ae. aegypti population to permethrin and lambda-cyhalothrin. Further studies should be conducted to determine the frequencies and changes among these kdr mutations and their role in the resistance to pyrethroids in the Region.

The early detection of resistance alleles is considered essential for the successful implementation of insecticide resistance management strategies by providing early warning for insect resistance.

The increasing urbanization and extensive usage of pesticides along with the rising levels of pyrethroid resistance in the Jazan region necessitate the early adoption of proactive monitoring and management programmes for insecticide resistance.

\section{Funding: None.}

Competing interests: None declared.

\section{Rôle des mutations entraînant une résistance knockdown (à l'effet de choc) dans la résistance aux pyréthrinoïdes chez Aedes aegypti en Arabie saoudite}

\section{Résumé}

Contexte : La dengue est endémique en Arabie saoudite, en particulier dans les régions d'Asir, de Djeddah, de Jazan et de la Mecque où les pyréthrinoïdes sont largement utilisés pour lutter contre le moustique Aedes aegypti, vecteur de la dengue. La résistance de cette espèce de moustique aux pyréthrinoïdes a été signalée dans la plupart de ces régions. L'élucidation de la base génétique sous-jacente d'une telle résistance devient donc importante.

Objectifs : La présente étude a été réalisée dans la Région de Jazan, dans le sud-ouest de l'Arabie saoudite, dans le but d'étudier le statut de la résistance d'Aedes aegypti aux pyréthrinoïdes et les mécanismes sous-jacents qui en découlent.

Méthodes: Trois pyréthrinoïdes (perméthrine, lambda-cyhalothrine et cyfluthrine) ont été utilisés pour étudier le statut de la résistance des moustiques adultes Aedes aegypti en suivant les méthodes standard de l'OMS. Les techniques d'amplification génique et de séquençage de l'ADN ont été utilisées pour détecter la mutation kdr S989P, V1016G et F1534C (mutation entraînant une résistance knockdown dite kdr).

Résultats : Les populations Aedes aegypti étaient sensibles à la cyfluthrine, pouvaient présenter une résistance à la perméthrine et montraient une résistance à la lambda-cyhalothrine. Trois mutations kdr potentielles ont été détectées pour la première fois dans la population Aedes aegypti, à savoir F1534C, V106G et S989P. En outre, il a été constaté que 
F1534C coexistait souvent avec V1016G et que cet haplotype était fortement associé à la résistance à la perméthrine et à la lambda-cyhalothrine. Par ailleurs, la mutation S989P a été détectée en tant que risque relatif dans 18,8\% des cas avec un taux de fréquence bas de 18,8\% et dans 55,5\% des cas avec un taux de 58,3\% chez les moustiques femelles résistantes à la perméthrine et à la lambda-cyhalothrine, respectivement.

Conclusions : La détection précoce des allèles de résistance devrait être considérée comme l'outil essentiel et indispensable pour assurer le succès de la mise en œuvre de stratégies de gestion de la résistance aux insecticides, en fournissant une alerte précoce de la résistance des insectes.

$$
\begin{aligned}
& \text { الطفر ات الجينية المساهمة في مقاومة بعوض الزاعجة المصرية لبعض المبيدات البيروثرويدية في المملكة العربية السعودية } \\
& \text { عمر دفع الله، عادل الشيخ، وحيد محمد، خالد شرواني، فراس الشيخ، يميى حباني، الصديق نور الدين } \\
& \text { الخالاصة }
\end{aligned}
$$

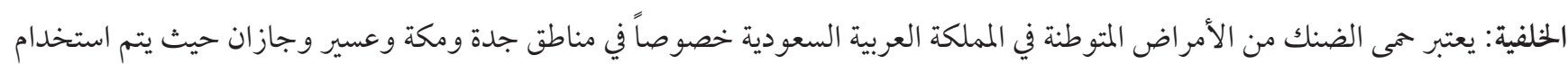

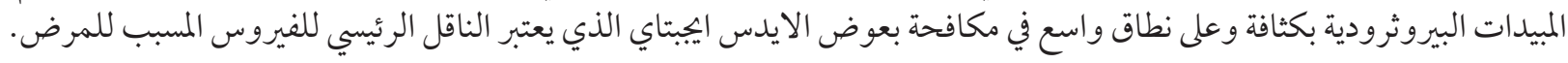

$$
\begin{aligned}
& \text { الأهداف: مقاومة بعوض الأيدس ايجبتاي للمبيدات البيروثرودية تم التوثيق لها من قبل في المناطق المذكورة. }
\end{aligned}
$$

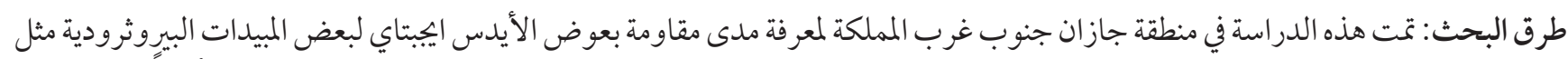

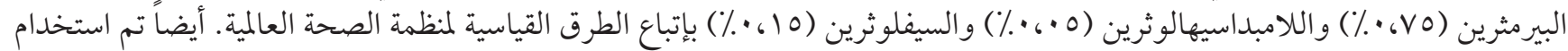

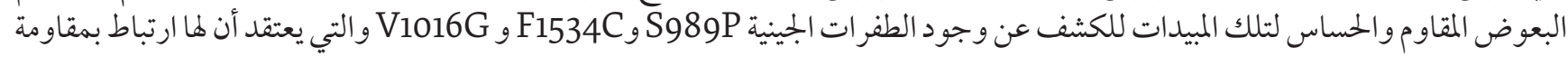

$$
\begin{aligned}
& \text { الحشر ات للمبيدات البيروثرودية. }
\end{aligned}
$$

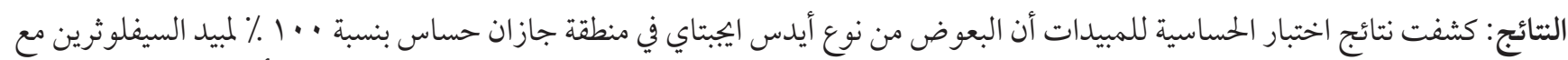

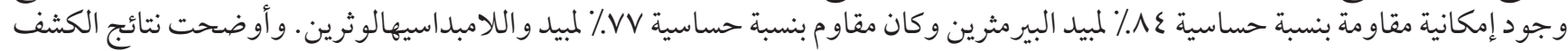

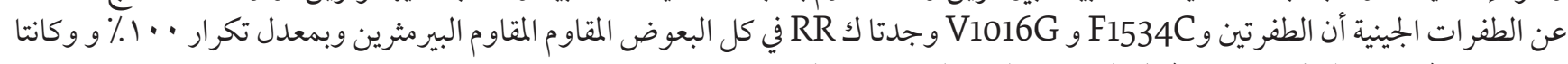

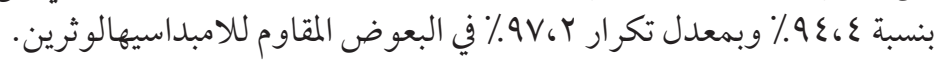

$$
\begin{aligned}
& \text { أيضاً كشفت الدر اسة بأن وجود الطفرة F1534C دائحاً ما تكون مرتبطة مع الطفرة V1016G وهذا المركب اظهر ارتباط قوي بالمقاومة لمبيدات } \\
& \text { البيرمثرين و اللامبداسيهالوثرين. }
\end{aligned}
$$

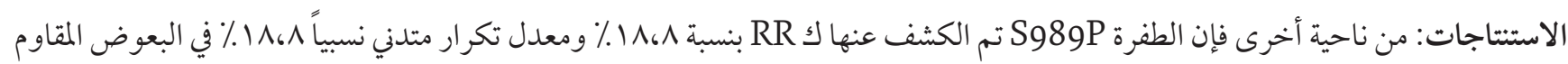

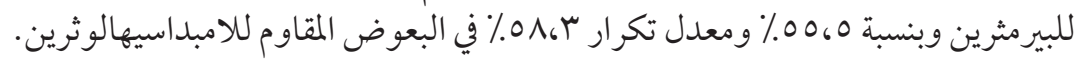

$$
\begin{aligned}
& \text { الزيادة في المناطق الحضرية والاستخدام المكثف للمبيدات في برامج الماتِ المكافحة وارتفاع مستوى المقاومة في نواقل الأمراض يتطلب تبني برامج }
\end{aligned}
$$

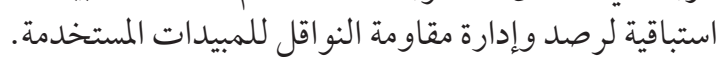

\section{References}

1. Dengue: guidelines for diagnosis, treatment, prevention and control: new edition. Geneva: World Health Organization; 2009 (WHO/HTM/NTD/DEN/2009.1).

2. Al Nazawi AM, Aqili J, Alzahrani M, McCall PJ, Weetman D. Combined target site (kdr) mutations play a primary role in highly pyrethroid resistant phenotypes of Aedes aegypti from Saudi Arabia. Parasit Vectors. 2017 Mar 27;10(1):161. doi:10.1186/s13071-0172096-6

3. Dengue control programme. Jazan: Ministry of Health, Department of Vector-Borne and Zoonotic Diseases; 2018.

4. Soderlund DM, Knipple DC. The molecular biology of knockdown resistance to pyrethroid insecticides. Insect Biochem Mol Biol. 2003 Jun 30;33(6):563-77. doi:10.1016/s0965-1748 (03)00023-7

5. Vontas J, Moore S, Kleinschmidt I, Ranson H, Lindsay S, Lengeler C, et al. Framework for rapid assessment and adoption of new vector control tools. Trends Parasitol. 2014 Apr 30;30(4):191-204. do:10.1016/j.pt.2014.02.005

6. Brengues C, Hawkes NJ, Chandre F, McCarroll L, Duchon S, Guillet P, et al. Pyrethroid and DDT cross-resistance in Aedes aegypti is correlated with novel mutations in the voltage-gated sodium channel gene. Medical and veterinary entomology. 2003 Mar 1;17(1):87-94. doi:10.1046/j.1365-2915.2003.00412.x

7. Yanola J, Somboon P, Walton C, Nachaiwieng W, Prapanthadara LA. A novel F1552/C1552 point mutation in the Aedes aegypti voltage-gated sodium channel gene associated with permethrin resistance. Pesticide Biochem Physiol. 2010 Mar 31;96(3):127-31. doi:10.1016/j.pestbp.2009.10.005

8. Kawada H, Oo SZ, Thaung S, Kawashima E, Maung YN, Thu HM, et al. Co-occurrence of point mutations in the voltage-gated 
sodium channel of pyrethroid-resistant Aedes aegypti populations in Myanmar. PLoS Negl Trop Dis.. 2014 Jul 31;8(7):e3032. doi. org/10.1371/journal.pntd.0003032

9. Alvarez LC, Ponce G, Oviedo M, Lopez B, Flores AE. Susceptibility status of Aedes aegypti (L.) (Diptera: Culicidae) to temephos in Venezuela. Pest Manag Sci. 2014 Aug 1;70(8):1262-6. doi:10.1002/ps.3688

10. Srisawat R, Komalamisra N, Eshita Y, Zheng M, Ono K, Itoh TQ, et al. Point mutations in domain II of the voltage-gated sodium channel gene in deltamethrin-resistant Aedes aegypti (Diptera: Culicidae). Appl Entomol Zool. 2010 May 25;45(2):275-82. doi:/10.1303/aez.2010.275

11. Kasai S, Ng LC, Lam-Phua SG, Tang CS, Itokawa K, Komagata O, et al. First detection of a putative knockdown resistance gene in major mosquito vector, Aedes albopictus. Japan J Infect Dis. 2011 May 1;64(3):217-21. doi: 10.1371/journal.pntd.0002948

12. Chen H, Li K, Wang X, Yang X, Lin Y, Cai F, et al. First identification of kdr allele F1534S in VGSC gene and its association with resistance to pyrethroid insecticides in Aedes albopictus populations from Haikou City, Hainan Island, China. Infect Dis Poverty. 2016 May 2;5(1):31. doi:10.1186/s40249-016-0125-x

13. Xu J, Bonizzoni M, Zhong D, Zhou G, Cai S, Li Y, et al. Multi-country survey revealed prevalent and novel F1534S mutation in voltage-gated sodium channel (VGSC) gene in Aedes albopictus. PLoS neglected tropical diseases. 2016 May 4;10(5):e0004696. doi.org/10.1371/journal.pntd.0004696

14. Marcombe S, Farajollahi A, Healy SP, Clark GG, Fonseca DM. Insecticide resistance status of United States populations of Aedes albopictus and mechanisms involved. PloS one. 2014 Jul 11;9(7):e101992. doi.org/10.1371/journal.pone.0101992

15. Alsheikh A, Mohammed W, Noureldin E, Daffalla O, Shrwani K, Hobani Y, et al. Resistance status of Aedes aegypti to insecticides in the Jazan Region of Saudi Arabia. Biosci, Biotech Res Asia. 2016;13(1):155-62. doi:10.13005/bbra/2018

16. Aziz A, Dieng H, Abu Hassan A, Satho T, Miake F, Salmah MRC, et al. Insecticide susceptibility of the dengue vector Aedes aegypti (Diptera: culicidae) in Makkah City, Saudi Arabia. Asian Pacific J Trop Dis. 2011;1(2):94-9. doi:10.1016/s2222-1808(11)60044-3

17. Al-Ghamdi KM, Al-Fifi ZI, Saleh MS, Al-Qhtani HA, Mahyoub JA. Insecticide susceptibility of Aedes aegypti, the vector of dengue fever in Jeddah governorate, Saudi Arabia. Biosciences Biotechnol Res Asia. 2008 December;5(2):501-6.

18. Al-Sheik AA. Larval habitat, ecology, seasonal abundance and vectorial role in malaria transmission of Anopheles arabiensis in Jazan Region of Saudi Arabia. J Egypt Soc Parasitol. 2011 Dec;41(3):615-34.

19. Guidelines for testing mosquito adulticides for indoor residual spraying and treatment of mosquito nets. Geneva: World Health Organization; 2006.

20. Test procedures for insecticide resistance monitoring in malaria vector mosquitoes, 2nd ed. Geneva: World Health Organization; 2016.

21. Li CX, Kaufman PE, Xue RD, Zhao MH, Wang G, Yan T, et al. Relationship between insecticide resistance and kdr mutations in the dengue vector Aedes aegypti in Southern China. Parasit Vectors. 2015 Jun 12;8:325. doi:10.1186/s13071-015-0933-Z

22. Altschul SF, Madden TL, Schäffer AA, Zhang J, Zhang Z, Miller W, et al. 1997. Gapped BLAST and PSI-BLAST: a new generation of protein database search programs. Nucleic Acids Res. 25(17):3389-402. doi:rg/10.1093/nar/25.17.3389

23. Alsheikh AA, Zafer MH, Anaami AG, Solan YM, Noureldin EM, Mohammed WS, et al. Potential mosquito vectors of arboviral diseases in Jazan Region, Saudi Arabia. Biosci Biotech Res Comm. 2013;6 (2),142-9.

24. Smith LB, Kasai S, Scott JG. Pyrethroid resistance in Aedes aegypti and Aedes albopictus: Important mosquito vectors of human diseases. Pesticide Biochem Physiol. 2016 Oct 1;133:1-2. doi10.1016/j.pestbp.2016.03.005

25. Thongwat D, Bunchu N. Susceptibility to temephos, permethrin and deltamethrin of Aedes aegypti (Diptera: Culicidae) from Muang district, Phitsanulok Province, Thailand. Asian Asian Pacific J Trop Med. 2015 Jan 1;8(1):14-8. doi:10.1016/s19957645(14)60180-2

26. Sharma SN, Saxena VK, Lal S. Study on susceptibility status in aquatic and adult stages of Aedes aegypti and Ae. albopictus against insecticides at international airports of south India. The Journal of communicable diseases. 2004 Sep;36(3):177-81. doi:10.24321/0019.5138.201720

27. Chareonviriyaphap T, Bangs MJ, Suwonkerd W, Kongmee M, Corbel V, Ngoen-Klan R. Review of insecticide resistance and behavioral avoidance of vectors of human diseases in Thailand. Parasit Vectors. 2013;6:280. doi:10.1186/1756-3305-6-280.

28. Narahashi T. Neuronal ion channels as the target sites of insecticides. Pharmacol Toxicol. 1996 Jul;79(1):1-14. https://doi. org/10.1111/j.1600-0773.1996.tbo0234.x

29. Rinkevich FD, Du Y, Dong K. Diversity and convergence of sodium channel mutations involved in resistance to pyrethroids. Pestic Biochem Physiol. 2013 Jul 31;106(3):93-100. doi10.1016/j.pestbp.2013.02.007

30. Wuliandari JR, Lee SF, White VL, Tantowijoyo W, Hoffmann AA, Endersby-Harshman NM. Association between three mutations, F1565C, V1023G and S996P, in the voltage-sensitive sodium channel gene and knockdown resistance in Aedes aegypti from Yogyakarta, Indonesia. Insects. 2015 Jul 23;6(3):658-85. doi10.3390/insects6030658

31. Vontas J, Kioulos E, Pavlidi N, Morou E, Della Torre A, Ranson H. Insecticide resistance in the major dengue vectors Aedes albopictus and Aedes aegypti. Pestic Biochem Physiol. 2012 Oct 31;104(2):126-31. doi:10.1016/j.pestbp.2012.05.008

32. Du Y, Nomura Y, Satar G, Hu Z, Nauen R, He SY, et al. Molecular evidence for dual pyrethroid-receptor sites on a mosquito sodium channel. Proceedings of the National Academy of Sciences. 2013 Jul 16;110(29):11785-11790. doi:10.1073/pnas.1305118110 
33. Saavedra-Rodriguez K, Urdaneta-Marquez L, Rajatileka S, Moulton M, Flores AE, Fernandez-Salas I, et al. A mutation in the voltage-gated sodium channel gene associated with pyrethroid resistance in Latin American Aedes aegypti. Insect molecular biology. 2007 Dec 1;16(6):785-98. doi:10.1111/j.1365-2583.2007.00774.X

34. Du Y, Nomura Y, Zhorov BS, Dong K. Sodium channel mutations and pyrethroid resistance in Aedes aegypti. Insects. 2016 Oct 31;7(4):60. doi:10.3390/insects7040060

35. Stenhouse SA, Plernsub S, Yanola J, Lumjuan N, Dantrakool A, Choochote W, et al. Detection of the V1016G mutation in the voltage-gated sodium channel gene of Aedes aegypti (Diptera: Culicidae) by allele-specific PCR assay, and its distribution and effect on deltamethrin resistance in Thailand. Parasit Vectors. 2013 Aug 30;6(1):253. doi:10.1186/1756-3305-6-253

36. Hirata K, Komagata O, Itokawa K, Yamamoto A, Tomita T, Kasai S. A single crossing-over event in voltage-sensitive Na+ channel genes may cause critical failure of dengue mosquito control by insecticides. PLoS neglected tropical diseases. 2014 Aug 28;8(8):e3085. doi:10.1371/journal.pntd.0003085

37. Vera-Maloof FZ, Saavedra-Rodriguez K, Elizondo-Quiroga AE, Lozano-Fuentes S. Black IV WC. Coevolution of the Ile1, o16 and Cys1, 534 mutations in the voltage gated sodium channel gene of Aedes aegypti in Mexico. PLoS Negl Trop Dis. 2015 Dec 11;9(12):e0004263. doi:10.1371/journal.pntd.0004263

38. Linss JG, Brito LP, Garcia GA, Araki AS, Bruno RV, Lima JB, et al. Distribution and dissemination of the Valio16Ile and Phe1534Cys Kdr mutations in Aedes aegypti Brazilian natural populations. Parasit Vectors. 2014 Jan 15;7:25. doi:10.1186/1756-3305-7-25 